\section{Aproximando Universidade e Escola Técnica: Lições Aprendidas com o Incentivo à Pesquisa no Ensino Médio Profissionalizante}

\author{
Bringing Together University and Technical School: Lessons \\ Learned with the Promotion of Research in Vocational High \\ School
}

\section{RESUMO}

$\mathrm{O}$ artigo descreve um estudo de monitoramento dos resultados das atividades de um projeto de aproximação entre universidade e escola técnica, em curso desde 2011, no Vale do Ribeira-SP, que reúne docentes do Instituto de Psicologia da USP, professores e estudantes das escolas técnicas dos municípios de Registro e Iguape. Por meio de questionários aplicados junto aos professores das escolas técnicas, entrevistas em grupo com os estudantes, leitura de relatórios elaborados por eles e conteúdos de um vídeo contendo suas narrativas, descreve-se os efeitos do projeto para a turma de estudantes do ano de 2012. A análise dos dados priorizou os ganhos formativos e pessoais dos estudantes com a participação no projeto, descrevendo seu desempenho e progresso. $\mathrm{O}$ estudo de monitoramento mostrou que a participação no projeto favoreceu aquisições de caráter acadêmico e relacional dos estudantes, contribuindo para que melhorassem suas habilidades de leitura e escrita, a organizar melhor os materiais de estudo, a ampliar sua capacidade de trabalhar em equipe e de cumprir prazos para realização de atividades. $\mathrm{O}$ artigo discute o potencial de iniciativas dessa natureza para valorização do intercâmbio entre universidade e escola pública e integração entre pesquisa e extensão universitária.

Palavras-chave: Extensão. Iniciação Científica. Ensino Médio Profissionalizante.

\section{ABSTRACT}

The article describes a monitoring study of the results about the activities from an ongoing project between the university and technical school, since 2011 in the Vale do Ribeira-SP. This project connects professors of the Psychology Institute at USP, teachers and students of technical schools, located in Registro and Iguape districts in the region. In order to collect data about the effects of the project from the class of students in 2012, methods used included questionnaires with teachers of technical schools, focal groups discussion with students, reading reports prepared by them
ALESSANDRO DE

Oliveira dos

SANTOS, BERNARDO

Parodi Svartman,

Fernando Viana de

Carvalho Rocco,

Luis Guilherme

GaLeño-SiLVA,

Ricardo Casco e

Gustavo Martineli

Massola

Universidade de São Paulo. Instituto de Psicologia, São Paulo, Brasil 
and video recordings about their narratives. Data analysis prioritized the training and personal gains of students who took part in the project in 2012, describing their performance and progress. The monitoring study showed that participation in the project favored academic and relational acquisitions of students, contributing to the improvement on their reading and writing skills, to be able to better organize the study materials, expand their capacity to work in teams and to respect deadlines for carrying out activities. The article discusses the potential of such initiatives to promote the interchange between university and public school and the integration between research and university extension.

Keywords: Extension. Scientific Initiation. High School.

\section{INTRODUÇÃO}

As universidades são instituições sociais comprometidas com a produção e a difusão do conhecimento científico. Para isso, têm estruturado sua atuação no tripé ensino, pesquisa e extensão. A capacidade de atuação nesse tripé tem sido reconhecida como fator de excelência dessas instituições para formar profissionais e cidadãos comprometidos com questões relevantes para a sociedade brasileira [7].

Nesse contexto, projetos que articulam pesquisa e extensão, aproximando universidade e escola, têm ganhado destaque por se configurarem como iniciativas formativas com potencial para a produção e a popularização do conhecimento científico. Diversos estudos têm discutido iniciativas desse tipo $[1 ; 2 ; 3 ; 9 ; 11 ; 13]$, apontando seus benefícios para a melhoria da qualidade da educação no Brasil. São iniciativas voltadas para o reconhecimento e inclusão de diferentes segmentos sociais e para a ampliação da capacidade de atuação da universidade na esfera pública.

Segundo Pereira, Nascimento e Pereira [9] o atual contexto de transformações e avanços tecnológicos e informacionais requer uma melhor qualificação técnico-científica dos jovens, tendo em vista sua formação profissional e cidadã, enquanto condições importantes para a atuação na vida em sociedade. Os autores defendem que a universidade tem um papel importante junto à escola no sentido de estimular o interesse do jovem pelo conhecimento científico, e que a extensão universitária é o melhor caminho para que isso se efetive.

Inserir o estudante de uma escola de ensino médio ou de ensino médio profissionalizante no ambiente acadêmico, dando-lhe oportunidades de experienciar os modos de construção do conhecimento científico e conhecer as pesquisas que vêm sendo desenvolvidas na universidade, num diálogo entre o que se aprende em sala de aula e os fenômenos da vida social, torna, segundo Heck et al [5] “(...) o aprendizado mais atrativo e prazeroso, uma vez que [os estudantes] podem desenvolver rapidamente a capacidade de processar uma informação nova, armazená-la e, fundamentalmente, torná-la útil”. Teixeira et al [13] destacam como benefícios da aproximação entre o ambiente escolar e o acadêmico: a ampliação da capacidade dos estudantes da escola de analisar e sintetizar conteúdos do ensino médio; a melhora da sua comunicação e da expressão oral e escrita; o desenvolvimento da habilidade 
de trabalhar em equipe; e o aumento da criatividade e iniciativa.

Os estudantes do ensino médio ou ensino médio profissionalizante formam um grupo com enorme potencial para a atuação das universidades, no intuito de cumprir sua missão de melhorar a qualidade do ensino e ao mesmo tempo difundir e popularizar a ciência e a tecnologia para os jovens e a sociedade em geral. A aproximação entre universidade e escola pode ajudar os jovens a trilhar o ingresso no ambiente acadêmico, visto que amplia o repertório de leitura e interpretação do mundo, contribuindo para formar um profissional e cidadão mais crítico e autônomo. Conforme Heck et al [5], iniciativas nessa direção proporcionam ao estudante de ensino médio: "uma experiência prévia e única sobre o ensino do qual fará parte em um futuro muito próximo, capacitando-o para adquirir seus conhecimentos de maneira mais independente".

Imbuídos dessa compreensão, desde 2011 docentes do Instituto de Psicologia da Universidade de São Paulo e do Centro Paula Souza de Educação Tecnológica, dedicam-se a um processo educativo e científico junto a estudantes das Escolas Técnicas (Etecs) dos municípios de Iguape e Registro no Vale do Ribeira-SP. Trata-se do projeto Revelando o turismo de base comunitária no Vale do Ribeira/SP que tem como objetivos: (I) descrever as iniciativas de turismo nas comunidades tradicionais da região, identificando suas estratégias de desenvolvimento e a relação com o mercado turístico; (II) sistematizar os principais resultados dessas iniciativas no que se refere ao fortalecimento comunitário e a geração de renda; (III) qualificar os estudantes do ensino médio profissionalizante da região em atividades de pesquisa.

Este artigo se relaciona com o objetivo (III) do projeto, descrevendo os ganhos formativos e pessoais dos estudantes que participaram das suas atividades em 2012. Os objetivos (I) e (II) do projeto, bem como os resultados alcançados, já foram descritos em outros estudos $[8 ; 12]$ e não serão tratados neste artigo. No ano de 2012 o projeto contou com a participação de 35 estudantes dos cursos de ensino médio profissionalizante de Turismo, Meio Ambiente, Administração, Informática e Agropecuária das Etecs dos municípios de Iguape e Registro, nove professores dessas ETEcs, que atuaram como supervisores dos estudantes nas escolas, e nove docentes do Instituto de Psicologia da USP. Por meio do Programa de Pré-Iniciação Científica os estudantes e professores das Etecs receberam uma bolsa de estudos por 12 meses no valor de $\mathrm{R} \$ 100,00$ para participar do projeto, o que possibilitou suas visitas às comunidades tradicionais do Vale do Ribeira e aos espaços de produção científica da Universidade de São Paulo.

Na primeira etapa do projeto buscou-se despertar o espírito de investigação do estudante por meio da definição de questões de pesquisa, mobilizando sua capacidade de prospectar soluções e de tomar decisões. Nesta etapa as atividades envolveram: reuniões semanais de orientação dos estudantes com o professor supervisor de sua Etec; reuniões mensais de planejamento com a participação de um professor da Etec e um docente do IP-USP, respectivamente, o supervisor e o orientador da sua proposta pessoal de investigação; leitura de textos sobre temas do projeto e sobre as comunidades que seriam investigadas; elaboração de perguntas para serem feitas aos moradores e lideranças das comunidades; simulações de procedimentos de coleta de dados, como a observação de campo e a realização de entrevistas. O intuito era a 
construção de propostas de investigação de interesse pessoal e coletivo, considerando que a sequência do desenvolvimento de uma investigação científica pressupõe três momentos ou índices distintos: inicial, formativo e final. O índice inicial diz respeito ao levantamento prévio do que os estudantes sabem sobre o tema que desejam investigar, quais são as suas hipóteses e referências de aprendizagem. $O$ índice formativo organiza as questões levantadas pelos estudantes e que deverão ser respondidas por meio de pesquisas individuais e/ou grupais, incluindo convites a conferencistas especializados no assunto, visitas a museus e exposições, apreciação de vídeos, leitura de bibliografia pertinente, entre outras atividades. O índice final, por sua vez, possibilita a tomada de consciência tanto dos saberes aprendidos como dos procedimentos mobilizados para a sua aquisição [6].

Na segunda etapa do projeto os estudantes foram para a USP e para as comunidades. As atividades realizadas por eles envolveram: visita aos espaços de produção científica do campus da USP - Cidade Universitária em São Paulo e visitas às comunidades, sendo a primeira visita destinada à observação de campo, a segunda para aplicação de entrevistas com moradores e lideranças das comunidades, e a terceira visita para devolutiva dos resultados às comunidades investigadas. Desse modo, o projeto compreendeu três movimentos: primeiro, a mobilização dos docentes do IP-USP que se deslocaram até as escolas de ensino médio profissionalizante do Vale do Ribeira-SP; segundo a mobilização dos estudantes dessas escolas para se deslocarem à Universidade; e, por fim, um terceiro movimento, caracterizado pela união entre docentes da Universidade e professores das escolas para, em conjunto com os estudantes, conhecerem as comunidades tradicionais do Vale do Ribeira e as iniciativas de turismo de base comunitário dessa região.

No ano de 2012 os estudantes das Etecs fizeram três viagens para atividades de campo junto a três comunidades do Vale do Ribeira-SP e quatro viagens aos espaços de produção científica da USP, incluindo a participação em seminários do projeto no Instituto de Psicologia da USP. As comunidades visitadas foram à vila caiçara do Marujá (município de Cananéia), o quilombo Ivaporunduva (município de Eldorado) e a aldeia Guarani Myba Pindo-ty (município de Pariquera Açú). Os espaços de produção científica visitados na USP, por sua vez, foram: a Faculdade de Arquitetura e Urbanismo, o Instituto Butantã, o Museu de Arte Contemporânea, o museu Paço das Artes, a Escola de Artes e Ciências Humanas (USP Leste) e o Instituto de Psicologia.

\section{MATERIAIS E MÉTODO}

Para descrever os efeitos do projeto sobre os estudantes de ensino médio profissionalizante das Etecs do Vale do Ribeira-SP, foi realizado um estudo de monitoramento dos resultados das atividades do projeto junto aos bolsistas de 2012. Um estudo de monitoramento envolve a coleta de dados e informações sobre os componentes de um projeto (recursos, atividades, resultados), de modo a acompanhar seu desenvolvimento e fornecer informações para adequações no projeto e para sua posterior avaliação [4]. 
Para a coleta de dados e informações visando o estudo de monitoramento foram utilizados questionários aplicados junto aos professores supervisores das Etecs e entrevistas em grupo, grupos focais, com estudantes. Além de informações obtidas por meio da leitura dos relatórios de pesquisa dos estudantes e do vídeo de formatura do Programa de Pré-Iniciação Científica da turma de 2012.

O questionário foi respondido pelos nove professores supervisores das Etecs, sendo cinco da Etec de Registro e quatro da Etec de Iguape e teve como objetivo verificar os efeitos do projeto na vida escolar dos estudantes. Desse modo, foi aplicado em dois momentos: no terceiro mês de participação do estudante no projeto, em Fevereiro de 2012, e após nove meses de sua participação, em Agosto de 2012.

As dimensões monitoradas por meio do questionário aplicado junto aos professores supervisores da Etecs foram: organização e sistematização pelos estudantes dos materiais de estudo; seus interesses pela leitura de textos como fontes de informação; sua capacidade de trabalho em equipe; sua capacidade para utilizar diversas linguagens para expressar ideias (oral e escrita).

As entrevistas com os estudantes, por sua vez, seguiram o formato de grupos focais e reuniram em média sete estudantes em cada grupo. Foram realizados dois grupos focais: o primeiro com alunos de Iguape e o segundo com alunos de Registro. Como fio condutor dos grupos focais, um roteiro de questões foi utilizado, incluindo perguntas como: "Fale-me um pouco sobre o tipo de contato que vocês tiveram com o projeto"; "Como foi o contato com o professor supervisor da Etec e o orientador da USP?"; “O que ficará como inesquecível para você em relação ao projeto?”.

Os facilitadores dos grupos focais foram estudantes bolsistas de Iniciação Científica e Cultura e Extensão do Curso de Psicologia do Instituto de Psicologia da USP, treinados para realização dessa atividade. As narrativas mobilizadas nos grupos focais foram gravadas em áudio e o conteúdo transcrito. Após a transcrição, leitura e releitura do material, foram identificados os conteúdos que diziam respeito às concepções dos estudantes das Etecs sobre o projeto, descritos os aspectos que apareceram de forma recorrente em suas narrativas, e feita uma análise de conteúdo das mesmas.

A análise dos dados coletados por meio do questionário e grupo focal priorizou o entendimento acerca dos ganhos formativos e pessoais dos estudantes com a participação no projeto, focalizando seu desempenho e progresso.

\section{RESULTADOS}

O estudo de monitoramento mostrou que a participação no projeto favoreceu aquisições de caráter acadêmico e relacional dos estudantes de ensino médio profissionalizante, tornando-os mais confiantes de forma que eles se sentissem mais seguros para realizar atividades de estudo e manifestar e defender seus pontos de vista. Como evidenciam as tabelas 1 e 2 - que apresentam as avaliações dos professores supervisores das Etecs a respeito do desempenho dos estudantes bolsistas em Fevereiro e 
Agosto de 2012 -, o projeto contribuiu para que melhorassem suas habilidades de leitura e escrita, a organizar melhor os materiais de estudo, a ampliar sua capacidade de trabalhar em equipe e o compromisso com o cumprimento de prazos e realização de atividades, de modo a não atrasar o andamento dos trabalhos em grupo.

Tabela 1 - Avaliação de estudantes bolsistas participantes do projeto por professores supervisores das Etecs em Fevereiro de 2012.

\begin{tabular}{|c|c|c|c|c|c|c|c|c|}
\hline \multirow[b]{2}{*}{ Cidade } & \multicolumn{2}{|c|}{ ORGANIZAÇÃO* } & \multicolumn{2}{|c|}{ LEITURA** } & \multicolumn{2}{|c|}{ EQUIPE*** } & \multicolumn{2}{|c|}{ LINGUAGEM**** } \\
\hline & Registro & Iguape & Registro & Iguape & Registro & Iguape & Registro & Iguape \\
\hline Excelente & 6 & 17 & 4 & 17 & 8 & 16 & 5 & 13 \\
\hline Bom & 25 & 18 & 25 & 24 & 22 & 19 & 23 & 30 \\
\hline Regular & 3 & 21 & 4 & 19 & 2 & 17 & 6 & 14 \\
\hline Ruim & 0 & 3 & 1 & 1 & 2 & 4 & 0 & 2 \\
\hline Não sabe & 0 & 0 & 0 & 0 & 0 & 0 & 0 & 0 \\
\hline
\end{tabular}

*Organização e sistematização do material de estudo; ${ }^{* \star I n t e r e s s e ~ p e l a ~ l e i t u r a ~ d e ~ t e x t o s ; ~}{ }^{\star \star \star * T r a b a l h o ~ e m ~ E q u i p e ; ~}{ }^{* \star \star * C a p a c i d a d e ~ d e ~ u t i l i z a r ~}$ diversas linguagens para expressar ideias.

Tabela 2 - Avaliação de estudantes bolsistas participantes do projeto por professores supervisores das Etecs em Agosto de 2012.

\begin{tabular}{|c|c|c|c|c|c|c|c|c|}
\hline \multirow[b]{2}{*}{ Cidade } & \multicolumn{2}{|c|}{ ORGANIZAÇÃO* } & \multicolumn{2}{|c|}{ LEITURA** } & \multicolumn{2}{|c|}{ EQUIPE*** } & \multicolumn{2}{|c|}{ LINGUAGEM $* * * *$} \\
\hline & Registro & Iguape & Registro & Iguape & Registro & Iguape & Registro & Iguape \\
\hline Excelente & 17 & 18 & 17 & 18 & 17 & 25 & 20 & 21 \\
\hline Bom & 16 & 27 & 14 & 23 & 16 & 15 & 13 & 29 \\
\hline Regular & 5 & 12 & 7 & 16 & 5 & 14 & 5 & 9 \\
\hline Ruim & 0 & 0 & 0 & 0 & 0 & 1 & 0 & 1 \\
\hline Não sabe & 0 & 0 & 0 & 0 & 0 & 0 & 0 & 0 \\
\hline
\end{tabular}

*Organização e sistematização do material de estudo; ${ }^{* \star I n t e r e s s e ~ p e l a ~ l e i t u r a ~ d e ~ t e x t o s ; ~}{ }^{\star \star \star T r a b a l h o ~ e m ~ E q u i p e ; ~}{ }^{\star \star \star *}$ Capacidade de utilizar diversas linguagens para expressar ideias. 
Quando comparadas as tabelas 1 e 2 percebe-se que os estudantes da Etec de Registro obtiveram melhora em diferentes dimensões no período monitorado. Quanto à organização e sistematização do material de estudo houve um aumento do quesito EXCELENTE. Também se verificou um sensível aumento no quesito REGULAR. Já na Etec de Iguape o quesito BOM aumentou em decorrência da diminuição das menções aos quesitos REGULAR e RUIM e o quesito EXCELENTE manteve-se.

Por ocasião da apresentação desses dados aos estudantes, muitos confirmaram que o projeto colaborou para a melhoria da organização e sistematização de seu material de estudo. Foram citados como exemplos a organização de pastas no computador e pen drive, bem como a utilização de caderno de registro ou diário de campo, pois passaram a anotar tudo que consideravam importante.

Em relação ao interesse pela leitura, comparando-se as tabelas 1 e 2, é possível observar na Etec de Registro um significativo aumento do quesito EXCELENTE. O quesito REGULAR também aumentou e ocorreu a redução do quesito RUIM. Na Etec de Iguape, por sua vez, a comparação das tabelas 1 e 2 mostra que o quesito EXCELENTE teve um pequeno aumento, os quesitos BOM e REGULAR diminuíram e o quesito RUIM desapareceu.

No que se refere à capacidade de trabalho em equipe dos estudantes, no questionário aplicado em Fevereiro de 2012, junto aos professores supervisores da Etec de Registro, este quesito foi considerado BOM, houve também menção ao quesito EXCELENTE e poucas notificações dos quesitos REGULAR e RUIM. No segundo momento de coleta de dados, em Agosto de 2012, notou-se um aumento do quesito EXCELENTE, o quesito RUIM desapareceu e o quesito REGULAR aumentou.

$\mathrm{Na}$ Etec de Iguape, por sua vez, desde o início, boa parte dos questionários aplicados junto aos professores supervisores apresentavam menções ao quesito EXCELEN$\mathrm{TE}$ e ao quesito $\mathrm{BOM}$ em relação aos estudantes que participaram do projeto. $\mathrm{E}$, no segundo momento de coleta de dados houve um aumento do quesito EXCELENTE e diminuição dos quesitos REGULAR e RUIM.

Já em relação à capacidade de utilizar diversas linguagens para expressar ideias (oral e escrita), comparando-se os dois momentos de coleta de dados, por meio do questionário aplicado junto aos professores das Etecs, percebe-se que na Etec de Registro ocorreu um aumento significativo do quesito EXCELENTE e a manutenção do quesito REGULAR. Enquanto na Etec de Iguape, por sua vez, houve aumento do quesito EXCELENTE, o quesito BOM manteve-se constante e ocorreu uma diminuição dos quesitos REGULAR e RUIM.

Nos grupos focais realizados com os estudantes das duas Etecs, por sua vez, foi recorrente o comentário de que cada estudante tinha suas obrigações específicas, o que os ajudou a adquirir responsabilidade e a sempre ajudar o grupo. Também houve críticas à realização de trabalho em conjunto, devido à postura de alguns colegas que, segundo uma estudante: "não fazem a sua parte".

No que se refere à atividade de grupo os estudantes das duas Etecs que participaram dos grupos focais enfatizaram a contribuição do projeto para a organização lógica de informações de trabalhos e o auxílio no planejamento, execução e postura durante a apresentação oral dos seus Trabalhos de Conclusão de Curso (TCCs). Também 
destacaram a colaboração do projeto para o desenvolvimento da comunicação com outras pessoas e a capacidade de adaptar a linguagem técnico-científica para realizar entrevistas e apresentar os resultados nas comunidades.

Os dados coletados por meio dos grupos focais permitiram configurar duas categorias que expressam os significados recorrentes atribuídos pelos estudantes ao projeto. São elas: $o$ projeto permitiu conhecer a região e $o$ projeto trouxe ganhos pessoais $e$ acadêmicos. Como exemplificam as narrativas a seguir dos estudantes:

a) O projeto permitiu conhecer a região:

"O Vale é a região mais pobre, está escrito na internet. Mas depois do estudo, a gente viu que o Vale é muito rico, com bastantes riquezas naturais, e tem muita gente que sai daqui porque não conhece esse lado da região. Eu gostaria que a região fosse conhecida não pelas falhas, mas pelas coisas boas, belezas naturais...”.

"As pessoas querem sair do Vale e ir pra fora, mas se tivessem a oportunidade de participar do projeto, teriam conhecimento das coisas boas da região e iam querer ficar aqui.".

b) O programa trouxe ganhos pessoais e acadêmicos:

"Tive a oportunidade de conhecer meus antepassados. Sempre tive vontade de conhecer e me aproximar do meu avô, e através do projeto, com as idas ao quilombo, pude ter essa aproximação. Quando eu vou lá agora (...) eu tenho descoberto sempre um novo familiar".

"Teve professores [da escola] que solicitaram como trabalho entrevistas e ficaram impressionados com o resultado, porque a gente aprendeu a abordar as pessoas, como fazer uma entrevista, encaixar as perguntas, saber elaborar uma questão para responder o que você quer saber. É uma bagagem que a gente vai levar para vida inteira”. "Eu achei que foi uma experiência muito rica. Primeiro pela oportunidade de ter o contato com estudantes de outras ETECs, professores de outras ETECs [...] por poder conhecer as comunidades [...] e por fim a oportunidade de ter um professor orientador, a gente até se sentia se preparando para um Mestrado, nos encaminhando para uma continuidade....

"Aumentou nossa autoestima, porque só por ter o nome USP já nos deixa orgulhosos. Eu fazia questão de vestir a camisa do projeto pra mostrar que eu fazia parte de um projeto em parceria com a USP."

Por meio dos grupos focais foi possível identificar mudanças importantes nos estudantes que participaram das atividades do projeto:

a) Os estudantes desenvolveram uma curiosidade para conhecer seu território e querem aprofundar esse conhecimento;

b) Os estudantes aprenderam a fazer uma pesquisa. Partiram da elaboração de perguntas, realizaram uma revisão da bibliografia e elaboraram um método que lhes permitisse coletar e analisar dados para responder essas perguntas;

c) O projeto foi um espaço integrador, por meio do qual foi possível amadurecer amizades, aproximar pessoas e estabelecer novos contatos. 
Em todos os relatos houve a constatação, exemplificada pela fala da estudante a seguir, de que: "a gente mora aqui, mas não conhece a riqueza histórica e cultural do Vale, e agora começamos a conhecer!”. Os frutos dessa descoberta aliada ao despertar da curiosidade científica, certamente influenciarão na trajetória futura de formação desses estudantes.

$\mathrm{Na}$ análise dos relatórios das pesquisas realizadas pelos estudantes, por sua vez, foi possível identificar informações semelhantes àquelas encontradas nos grupos focais. A análise dos relatórios mostra que a aproximação entre universidade e escola propiciada pelo projeto, permitiu ampliar o conhecimento sobre o território onde moram e trouxe ganhos de cunho formativo e pessoal, como exemplificam os trechos retirados dos relatórios e apresentados a seguir:

"A participação no projeto foi muito importante para melhorar os meus conhecimentos e perceber que ainda tem muitas culturas, costumes e tradições aqui tão perto de nós e que muitas vezes não conhecemos".

"Gostei muito de fazer entrevistas, conhecer outra cultura e novas pessoas, compartilhando histórias e experiências. As viagens também foram bem produtivas e me ajudaram a conhecer mais o patrimônio natural e cultural da nossa região".

"Nesse período de um ano pesquisando três comunidades tivemos o prazer de escutar histórias, aprender, nos divertir, crescer e voltar com uma devolutiva [para as comunidades] propondo uma ajuda, uma forma de estar presente ano que vêm com outra turma de alunos para continuar o projeto".

"Dentre os conhecimentos adquiridos, um dos mais importantes foi o de sempre valorizar suas raízes e lutar, não pensando no bem de uma minoria, mas pensando no bem de todos, atuais e futuras gerações".

"O projeto foi uma grande realização pessoal e profissional para mim. Através dele pude perceber a importância das culturas, as diferentes formas de se organizar em sociedade e a preservação do meio ambiente. (...) As viagens foram grandes experiências de convivência, contatos, informações e admiração com as paisagens e os diversos ambientes dos diversos lugares do Vale do Ribeira. Pude perceber como é interessante ouvir histórias, causas, fatos e consequências nas entrevistas, relatos de vidas que testemunharam acontecimentos muito importantes para o processo de desenvolvimento de seus locais".

"Este projeto trouxe várias oportunidades enquanto moradora do Vale do Ribeira de conhecer mais sobre minha região. O que pude acompanhar foi de grande conhecimento, que abriram áreas para poder estudar e refletir que antes talvez jamais foram exploradas. Pude aprender muitas coisas compartilhando conhecimento e recebendo conhecimento com meu grupo de pesquisa, tenho muito a agradecer a todos, pois o maior saber que poderemos sempre levar em nossas vidas é o conhecimento".

A formatura da turma de 2012 do Programa de Pré-Iniciação Científica foi outro momento no qual os estudantes puderam refletir sobre os efeitos do projeto em sua formação e na vida pessoal. $\mathrm{Na}$ formatura um estudante contou que:

“(...) foi um caminho um pouco mais difícil do que imaginávamos. Afinal, nenhum de nós estava acostumado a planejar uma pesquisa, a procurar metodologias adequadas a cada tipo de situação, a leituras intensas e buscas de artigos científicos. 
O momento onde tudo valia a pena era quando chegávamos às comunidades e colocávamos todos os conhecimentos em prática”.

Outro estudante destacou os benefícios da aproximação entre a escola e a universidade:

"As atividades desenvolvidas funcionaram como complemento às aulas do curso técnico, uma vez que muito daquilo que víamos em sala de aula era aplicado no projeto. Isto, contribuiu para ambos aos lados, acrescentado muito na minha vida escolar (...). A oportunidade de estar convivendo com professores mais experientes e compartilhar as experiências foi também um ponto que nos fortaleceu e nos deu força”.

A análise das narrativas coletadas no vídeo de formatura da turma de 2012 indica que por meio do projeto os estudantes obtiveram conhecimentos sobre as comunidades. Também obtiveram experiência em pesquisa, aprendendo a elaborar roteiros de questões e a realizar e analisar entrevistas com lideranças e moradores das comunidades. Ademais, o projeto aproximou os estudantes das Etecs da Universidade de São Paulo, visto que muitos pretendiam prestar o vestibular da FUVEST e que, por meio do projeto, tiveram oportunidade de conhecer a USP, como exemplifica a fala de um estudante: "Os melhores instantes vividos por todos foram os encontros na USP, mostrando pra gente que estudar lá não é um sonho impossível”.

\section{DISCUSSÃO E CONCLUSÕES}

O projeto Revelando o turismo de base comunitária no Vale do Ribeira/SP é uma experiência de aproximação entre a universidade e a escola que proporciona aos estudantes do ensino médio profissionalizante envolvidos, a oportunidade de vivenciar novas realidades e de aplicar conhecimentos adquiridos.

Uma série de lições puderam ser aprendidas com este projeto, em curso desde 2011 nas Etecs de Registro e Iguape no Vale do Ribeira-SP. Por meio do projeto os estudantes saem do seu cotidiano no ambiente escolar, adentrando o ambiente comunitário e o ambiente acadêmico com seus laboratórios e serviços técnicos, podendo vivenciar práticas especializadas. Tal experiência tem permitido aos estudantes de ensino médio profissionalizante a compreensão sobre objetos de conhecimento de seu interesse e a identificação do papel que o pesquisador tem na sua produção, estimulando a aprendizagem de ciências e a capacidade de comunicação (expressão oral e escrita), criatividade e iniciativa. Um dado interessante é que a realização do projeto também despertou o interesse por parte dos estudantes de graduação em Psicologia da USP, seja por meio da participação como bolsistas de Iniciação Científica ou de Cultura e Extensão ou como monitores em visitas dos estudantes das Etecs aos espaços de produção científica da Universidade.

Semelhante aos resultados encontrados pelos autores Garavello, Molina, Silva e Costa [3] ao analisarem o projeto de extensão conduzido por eles, constata-se as enormes possibilidades de intercâmbio entre conhecimento científico e saberes comunitários que projetos dessa natureza oferecem. Estes dois âmbitos, conhecimento científico e saberes locais, podem dialogar, como defendem o autores, de forma crítica 
e criativa, proporcionando a vivência de questões fundamentais que se colocam para a universidade, no que diz respeito à produção, difusão e popularização do conhecimento científico, e para as comunidades tradicionais, no que se refere à luta por sua sobrevivência e direitos.

Segundo Frias, Junqueira e Zilbovicius [2] “A extensão Universitária é o processo educativo e científico que articula o ensino e a pesquisa de forma indissociável e viabiliza a relação transformadora entre a universidade e a sociedade". Nesse sentido, as viagens e atividades de campo realizadas nas comunidades tradicionais pelos estudantes, ofereceram um espaço de treinamento intercultural e letramento étnico-racial e de aprendizagem sobre participação comunitária. Os estudantes tiveram que desenvolver a abordagem de campo e a aplicação de métodos de coleta de dados, a partir de negociações e acordos com lideranças comunitárias e nativos do meio rural que, muitas vezes, falam outra língua (tupi), utilizam dialeto (caipira), tem seus valores e costumes transmitidos de forma oral, lutam por seus direitos e afirmam sua identidade cultural e étnico-racial. Desse modo, gradualmente foi ganhando força no projeto a noção de comunidades interpretativas [10] como um elemento chave que guiou a construção dos procedimentos de investigação junto às comunidades tradicionais. Essa noção integra conhecimentos e visões de mundo dos saberes comunitários em pesquisas, conferindo a eles a mesma relevância interpretativa que recebem os conhecimentos científicos. Nesse sentido, o encontro entre universidade, escola e comunidades tradicionais seria um encontro de experts, ao reunir saberes de diferentes naturezas, mas de igual importância para a compreensão da realidade.

Ao mesmo tempo, as visitas dos estudantes das Etecs aos espaços de produção científica da USP permitiram aprofundar sua compreensão sobre as comunidades, por meio das reflexões consubstanciadas em seminários, do contato próximo com pesquisadores e pelo desenvolvimento e exercício de procedimentos científicos de investigação. Isso mostra a importância do engajamento dos docentes e pesquisadores da universidade na difusão e popularização do conhecimento científico, e a riqueza dos saberes advindos do contato direto entre escola, comunidades tradicionais e universidade.

A incorporação de novas mídias em projetos dessa natureza pode ser de grande valia, pois além de fazerem parte do cotidiano atual dos estudantes, ajudam a encurtar a distância física entre professores supervisores, docentes orientadores da universidade e os próprios estudantes, fortalecendo a integração das ações. No caso específico do projeto em curso, é possível citar como exemplo a criação de um blog que favorece um conjunto de ações pedagógicas como: tirar dúvidas dos estudantes, postar mensagens de orientação, criar uma agenda comum e uma biblioteca virtual acessível para todos.

Uma limitação do estudo de monitoramento realizado foi a ausência de um plano integrado de monitoramento e avaliação do projeto contendo indicadores como o grau de satisfação dos estudantes e professores das Etecs com o projeto e suas atividades. Além disso, não houve a definição de uma linha de base a partir da qual os resultados do monitoramento pudessem ser comparados, impedindo confrontar os resultados descritos com essa linha de base, de modo a verificar a magnitude e consistência das mudanças ocorridas nos estudantes das Etecs. Ademais, é importante 
destacar que os próprios dados produzidos pelo monitoramento poderiam trazer maiores informações se submetidos a tratamentos interpretativos mais avançados, permitindo confrontá-los, por exemplo, com um determinado campo teórico, submetendo-os a crítica.

Destarte, a força do estudo de monitoramento realizado reside no fato de ter propiciado a sistematização de um conjunto de informações importantes para a realização de projetos que visem aproximar universidade e escola pública, articulando pesquisa e extensão. Tais projetos devem incentivar o interesse dos estudantes de ensino médio e ensino médio profissionalizante pela atividade de pesquisa, oferecendo oportunidades de complemento da sua formação e aprimoramento de conhecimentos, inserção em espaços de produção científica para acompanhamento de investigações desenvolvidas e a convivência com pesquisadores e grupos de pesquisa.

\section{REFERENCIAS}

[1] CHINELATTO, A. S. A. et al. Extensão Universitária: Promovendo a Interação dos Cursos de Engenharia da UEPG com o Ensino Médio. Revista Conexão UEPG, v. 3, p. 31-34, 2007.

[2] FRIAS A. C; JUNQUIERA, S. R.; ZILBOVICIUS, C. Projeto Cananéia: Atividade de Extensão Universitária que integra Graduação. Serviço e Comunidade. Revista de Cultura e Extensão, v. 5, p. 65-71, 2011. DOI: 10.11606/issn.2316906o.v5iop65-71.

[3] GARAVELLO, M.E. P. E.; et al. Artesanato com fibra de bananeira: uma experiência no Vale do Ribeira, SP. Revista Cultura e Extensão USP, v. 3, p. 31-36, 2010. DOI: 10.11606/issn.2316-906o.v3iop31-36.

[4] HARTZ, Z. M. A. ( Org.). Avaliação em Saúde: dos modelos conceituais à prática na análise da implantação de programas. Rio de Janeiro: Fiocruz, 1997.

[5] HECK, T.G. et al. Iniciação Científica no Ensino Médio: um Modelo de Aproximação da Escola com a Universidade por Meio do Método Científico. Revista Brasileira de Pós-Graduação, v. 8, p. 447-465, 2012.

[6] HERNÁNDEZ, F.; MONTSERRAT, V.A organização do currículo por Projetos de Trabalho. Porto Alegre: Artmed, 1998.

[7] MARTINS, L. M. A indissociabilidade Ensino-Pesquisa-Extensão como um dos fundamentos metodológicos do Ensino Superior. In: PINHO, S. Z. (Org.). Oficinas de Estudos Pedagógicos: reflexões sobre a prática do Ensino Superior. São Paulo: Cultura Acadêmica: UNESP, 2008, p. 102-115.

[8] MASSOLA, G. M.; SANTOS, A. O.; MARTINS, A. B. M. Turismo de base comunitária: instrumento para o fortalecimento da gestão democrática em quilombos no Brasil. In: YANAZE, M. H.; ORTIZ, F. C.; MARKUS, K. (Orgs.). Marketing e comunicação de projetos socioculturais: experiências brasileiras e cubanas. São Caetano do Sul/SP: Difusão Editora, 2015, p. 279-303.

[9] PEREIRA, I. B.; NASCIMENTO, F. S.; PEREIRA, T. R. D. S. Articulação Universidade Ensino Médio: Potencialidades das Geotecnologias e o 
Conhecimento Científico. Anais do X Congresso Nacional de Educação EDUCERE: formação para mudanças no contexto da educação: políticas, representações sociais e práticas. Curitiba: PUCPR, 2011, p.6138 - 6150.

[10] SCHMIDT, M, L, S. Pesquisa Participante: alteridade e comunidades interpretativas. Psicologia USP, v. 17, n. 2, p.11-41, 2006. DOI: 10.1590/ So103-65642006000200002.

[11] SILVA, L. F. F. Projeto Bandeira Científica: História, Estratégias e Resultados. Revista Cultura e Extensão USP, v. 7, p. 53-65, 2012. DOI: 10.11606/issn.23169060.v7iop53-65.

[12] SVARTMAN, B.; SANTOS, A. O.; MARTINS, A.; CASCO, R.; SILVA, L. G. G.; MASSOLA, G. M. Recherche psychosociale dans des communautés traditionnelles: analyse de l'expérience du Programme de Pré-Initiation Scientifique de l'Université de São Paulo. Bulletin de Psychologie, v. 68, n. 2, p. 115-124, 2015. DOI: 10.3917/bupsy.536.0115.

[13] TEIXEIRA, E. P. et al. Engenharia no Ensino Médio. Educationg Engineers for Innovation - International Conference on Enginnering and Computer Education. Buenos Aires: IEEE - COPEC, 2009. v. 1. p. 1020-1024.

A LESSANDRO DE OLIVEIRA DOS SANTOS docente do Instituto de Psicologia da USP. Tem experiência nos temas relações étnico-raciais, conflitos socioambientais e turismo de base comunitária -e-mail:alos@usp.br.

BERNARDO PARODI SVARTMAN docente do Instituto de Psicologia da USP. Tem experiência nos temas juventude, movimentos sociais e participação política.

FERNANDO VIANA DE CARVALHO ROCCO mestrando do Instituto de Psicologia da USP. Bolsista da Pró-Reitoria de Cultura e Extensão em 2012 junto ao projeto Revelando o turismo de base comunitária no Vale do Ribeira/SP.

LUIS GUILHeRme GALẽ̃o-SILVA docente do Instituto de Psicologia da USP. Tem experiência nos temas violência e memória em comunidades tradicionais brasileiras e áreas de ocupação na cidade de São Paulo.

RICARDO CASCO pós-doutorando do Instituto de Psicologia da USP. Tem experiência nos temas juventude, relações de poder e violência nas instituições escolares.

GUSTAVO MARTINELI MASSOLA docente do Instituto de Psicologia da USP. Tem experiência nos temas enraizamento territorial e participação política, especialmente em comunidades tradicionais brasileiras e áreas de ocupação na cidade de São Paulo. 